controls. To the best of our knowledge, this is the first investigation in which monoclonality in mastocytosis has been demonstrated directly by a molecular biological technique. Our findings are consistent with those of two recently published studies, in which point mutations of the proto-oncogene c-kit were found in peripheral blood cells ${ }^{9}$ and mast cells of both skin and spleen $^{10}$ in mastocytosis. Additional DNA analysis by flow cytometry revealed no quantitative DNA abnormality severe enough to be detectable. The proliferation index of less than $8 \%$ indicates that malignant mastocytosis is a relatively slow growing tumour, compatible with the finding that, in this disease, the extent of mast cell infiltration often remains stable in serial biopsies.

No definite conclusions can be drawn about the biological nature of the mastocytoses from this study because of the small number of cases included and the fact that it may vary among the various different subtypes of mastocytosis. Further molecular biological investigations on defined subtypes are therefore planned.

The authors thank Dako Diagnostica GmbH, Hamburg, Germany, for contribution towards the cost of reproduction of the colour artwork.
1 Kirshenbaum AS, Kessler SW, Goff JP, Metcalfe DD. Demonstration of the origin of human mast cells from CD34+ bone marrow progenitor cells: F Immunol 1991;146:1410 15.

2 Allen RC, Zoghbi HY, Moseley AB, Rosenblatt HM, Belmont JW. Methylation of HpaII and HhaI sites near the polymorphic CAG repeat in the human androgen-receptor gene correlates with $\mathrm{X}$ chromosome inactivation. $\mathrm{Am} \mathcal{F}$ Hum Genet 1992;51:1229-39.

3 Mutter GL, Chaponot ML, Fletcher JA. A polymerase chain reaction assay for non-random $\mathrm{X}$ chromosome inactivation identifies monoclonal endometrial cancers and precancers. Am $\mathcal{F}$ Pathol 1995;146:501-8.

4 Miltenyi S, Müller W. Weichel W, Radbruch A. High gradient magnetic cell separation with MACS. Cytometry 1990;11:231-8.

5 Hedley DW, Friedlander ML, Taylor IW. Method for analysis of cellular DNA content of paraffin-embedded pathological material using flow cytometry. 7 Histochem Cytochem 1983;31:1333-5.

6 Busque L, Gilliland DG. Clonal evolution in acute myeloid leukemia. Blood 1993;82:337-42.

7 Willman CL, Busque L, Griffith BB, Favara BE, McClain $\mathrm{KL}$, Duncan $\mathrm{MH}$, et al. Langerhans'-cell histiocytosis (histiocytosis X) - a clonal proliferative disease. $N$ Engl $f$ Med 1994;331:154-60.

8 Mashal RD, Lester SC, Sklar J. Clonal analysis by study of $\mathrm{X}$ chromosome inactivation in formalin-fixed paraffinembedded tissue. Cancer Res 1993;53:4676-9.

9 Nagata H. Worobec AS, Oh CK, Chowdhury BA, Tannenbaum S, Suzuki Y, et al. Identification of a point mutation in the catalytic domain of the protooncogene c-kit in peripheral blood mononuclear cells of patients who have mastocytosis with an associated hematologic disorder. Proc

10 Longley BJ, Tyrrell L, Lu S-Z, Ma Y-S, Langley K, Ding T-G, et al. Somatic c-KIT activating mutation in urticaria pigmentosa and aggressive mastocytosis: establishment of clonality in a human mast cell neoplasm. Nat Genet 1996; 12:312-14.
Department of

Gastroenterology, Centre for Digestive

Diseases, Leeds

General Infirmary,

Great George Street,

Leeds LS1 3EX, United

Kingdom

P Moayyedi

S O'Mahony

D A F Lynch

A T R Axon

Department of Histopathology P Jackson

M F Dixon

Correspondence to:

Dr Moayyedi.

Accepted for publication 25 February 1997

\title{
Small intestine in lymphocytic and collagenous colitis: mucosal morphology, permeability, and secretory immunity to gliadin
}

\author{
P Moayyedi, S O’Mahony, P Jackson, D A F Lynch, M F Dixon, A T R Axon
}

\section{Abstract}

There is a recognised association between the "microscopic" forms of colitis and coeliac disease. There are a variety of subtle small intestinal changes in patients with "latent" gluten sensitivity, namely high intraepithelial lymphocyte (IEL) counts, abnormal mucosal permeability, and high levels of secretory $\operatorname{IgA}$ and $\operatorname{IgM}$ antibody to gliadin. These changes have hitherto not been investigated in microscopic colitis. Nine patients (four collagenous, five lymphocytic colitis) with normal villous architecture were studied. Small intestinal biopsies were obtained by Crosby capsule; small intestinal fluid was aspirated via the capsule. IEL counts were expressed per 100 epithelial cells, and intestinal IgA and IgM antigliadin antibody levels were measured by ELISA. Small intestinal permeability was measured by the lactulose:mannitol differential sugar permeability test. IEL counts were normal in all cases, median 17 , range 7-30. Intestinal antigliadin antibodies were measured in six cases and were significantly elevated in two patients (both IgA and IgM). Intestinal permeability was measured in eight cases and was abnor$\mathrm{mal}$ in two and borderline in one. These abnormalities did not overlap: four of nine patients had evidence of abnormal small intestinal function. Subclinical small intestinal disease is common in the two main forms of microscopic colitis. (F Clin Pathol 1997;50:527-529)

Keywords: lymphocytic and collagenous colitis; coeliac disease; intraepithelial lymphocyte counts; IgA; IgM

The increasing use of colonoscopy has allowed the identification of a group of patients with chronic watery diarrhoea who have minimal macroscopic changes but microscopic evidence of mucosal inflammation. Read et al ${ }^{1}$ coined the term "microscopic colitis" to describe this 
Table 1 Summary of small bowel abnormalities in patients with lymphocytic and collagenous colitis

\begin{tabular}{lllllll}
\hline & & & $\begin{array}{l}\text { Antigliadin } \\
\text { IgA (normal } \\
\text { OD } \leqslant \text { 15) }\end{array}$ & $\begin{array}{l}\text { Antigliadin } \\
\text { IgM (normal } \\
\text { OD } \leqslant \text { 15) }\end{array}$ & $\begin{array}{l}\text { L:M ratio } \\
\text { (normal } \\
<0.07)\end{array}$ & $\begin{array}{l}\text { IELs (normal } \\
10-40 \text { IEL/100 } \\
\text { epithelial cells) }\end{array}$ \\
\hline Lymphocytic & 61 & F & $\mathbf{1 6 . 0}$ & $\mathbf{2 0 . 2}$ & ND & 17 \\
Lymphocytic & 36 & F & 1.0 & 5.3 & 0.07 & 19 \\
Lymphocytic & 65 & M & ND & ND & 0.03 & 7 \\
Lymphocytic & 55 & F & ND & ND & $\mathbf{0 . 1 6}$ & 14 \\
Lymphocytic & 22 & F & 0.5 & 13.5 & 0.01 & 15 \\
Collagenous & 48 & F & ND & ND & 0.02 & 28 \\
Collagenous & 76 & M & $\mathbf{1 8 . 4}$ & $\mathbf{5 3 . 0}$ & 0.03 & 20 \\
Collagenous & 52 & F & ND & ND & 0.01 & 30 \\
Collagenous & 49 & F & 4.0 & 11.4 & $\mathbf{0 . 1 5}$ & 11
\end{tabular}

Abnormal values in bold.

OD, optical density; IEL, intraepithelial lymphocytes; ND, not done; L:M, lactulose:mannitol

clinical syndrome; subsequent studies have suggested that most of these cases could be further subdivided into two distinct histological conditions, "lymphocytic colitis" and "collagenous colitis". There remain, however, some cases in which there is no intraepithelial lymphocytosis and no increase in subepithelial collagen to whom the unqualified term "microscopic colitis" is still applied. Whether these cases represent a further distinct entity or are simply a stage in the evolution of lymphocytic or collagenous colitis remains a moot point.

The aetiology of these conditions is unknown but there are case reports of an association between both lymphocytic and collagenous colitis and coeliac disease. ${ }^{3}$ Classically, coeliac disease is characterised by subtotal villous atrophy but we now recognise that there are more subtle manifestations of gluten sensitivity in patients with normal villous architecture. ${ }^{4}$ These include increased jejunal intraepithelial lymphocytes (IEL), ${ }^{4}$ high concentrations of mucosal antigliadin IgM and IgA antibody (coeliac intestinal antibody (CIA) pattern, ${ }^{56}$ or abnormal small bowel permeability. ${ }^{7}$

Given the known association between coeliac disease and microscopic colitis we hypothesised that patients with normal small bowel villous architecture might have evidence of subclinical gluten sensitivity (CIA pattern) or subtle evidence of small intestinal dysfunction (abnormal permeability). We evaluated the IEL, mucosal antigliadin antibodies, and permeability of the jejunum in patients with microscopic colitis but normal villous architecture.

\section{Methods}

Cases classified as "microscopic colitis" were identified by a computer review of the index of pathology diagnoses at the Leeds General Infirmary. Patients with coeliac disease were excluded. All patients complained of watery diarrhoea for at least six months and upper gastrointestinal endoscopy, small bowel meal, and colonoscopy were macroscopically normal. Multicolonic biopsies were obtained and patients were classified as having lymphocytic or collagenous colitis on histological criteria. All biopsies were fixed in $10 \%$ buffered formalin solution and haematoxylin and eosin stains of paraffin wax embedded sections were examined by a single experienced gastrointestinal pathologist (MFD). Patients with increased colonic IEL counts of $>20$ lymphocytes per 100 surface epithelial cells, surface epithelial damage, and normal crypt architecture were defined as having lymphocytic colitis. ${ }^{2}$ Patients with thickening of the collagenous band beneath the basement membrane in addition to an increase in IEL were defined as having collagenous colitis. ${ }^{2}$ Local research ethics committee approval was obtained.

Patients were invited to attend for a small bowel biopsy. This was performed by endoscopically placing a Crosby capsule in the distal duodenum. Small intestinal fluid was aspirated through the Crosby capsule tubing and a protease inhibitor was immediately added $(100 \mathrm{mmol} / \mathrm{l}$ phehylmethylsulphonyl fluoride, $20 \mu \mathrm{l} / \mathrm{ml}$ of aspirate) before storage at $-70^{\circ} \mathrm{C}$. The Crosby capsule was then fired, the distal duodenal mucosa was formalin fixed and examined by a consultant pathologist for morphological changes consistent with coeliac disease. Small bowel IEL counts were evaluated by a single observer with 10-40 IEL per 100 epithelial cells considered as the normal range. ${ }^{4}$

The concentration of IgA and IgM antibodies to gliadin, IgM antibodies to ovalbumin, and $\operatorname{IgM}$ antibodies to $\beta$ lactoglobin were assayed by an enzyme linked immunosorbent assay (ELISA) on the small bowel aspirate. Serum from a patient with untreated coeliac disease was used as a reference standard. A positive antibody result was defined as an optical density reading $>15$ compared with the positive control. ${ }^{6}$ Patients were defined as having a CIA pattern if anti-IgM to gliadin was positive plus at least two of anti-IgA to gliadin, anti-ovalbumin $\operatorname{Ig} M$, and anti- $\beta$ lactoglobin $\operatorname{IgM}$.

A lactose:mannitol differential sugar permeability test was also performed. A solution of $5 \mathrm{~g}$ lactulose and $2 \mathrm{~g}$ mannitol dissolved in $100 \mathrm{ml}$ of water was drunk after an overnight fast. Urine was collected over five hours and the two molecules were assayed. Results were expressed as a ratio (lactulose:mannitol) with $<0.07$ being considered normal. ${ }^{2}$

\section{Results}

Nine patients (seven females) with a median age of 52 years (range 22-76) were recruited. None of the patients was taking non-steroidal anti-inflammatory drugs (NSAIDs). Five patients had collagenous colitis and four had lymphocytic colitis. Small bowel mucosa was obtained in all cases, sugar permeability was assessed in eight patients, and jejunal aspirate sufficient for analysis was obtained in five cases. IEL counts were normal in all cases with a median of 17 lymphocytes per 100 epithelial cells (range 7-30). The small bowel villous architecture and villous crypt ratio were all normal. Sugar permeability was abnormal in two and borderline in one patient. CIA pattern (elevated mucosal antigliadin $\operatorname{IgA}$ and $\operatorname{IgM}$ antibody, anti-ovabumin $\operatorname{Ig} M$, and anti- $\beta$ lactoglobulin $\operatorname{IgM}$ ) was detected in two cases Serum antigliadin and anti-endomysial antibodies were normal in all patients. These abnormalities did not overlap and were divided 
equally in the lymphocytic and collagenous colitis groups (table 1).

Patients with a CIA pattern were reviewed. In both cases their diarrhoea had resolved and one refused further investigation. The other patient was given a challenge of $20 \mathrm{~g}$ of gluten per day in addition to their normal diet. Repeat small bowel biopsies six weeks later were again normal and the patient's symptoms did not deteriorate.

\section{Discussion}

This is the first study of small intestinal function in patients with microscopic colitis and our hypothesis that these patients may have subclinical gluten sensitivity has been partly confirmed. We found abnormal small intestinal permeability in two subjects (one collagenous, one lymphocytic colitis); we detected a CIA pattern in a further two patients (one collagenous, one lymphocytic colitis). IEL populations were normal in all nine cases. We have therefore detected abnormalities of small bowel function characteristically associated with coeliac disease/gluten sensitivity in four of the nine $(45 \%)$ patients.

CIA pattern suggests abnormal mucosal immunity to gliadin and is a putative marker for latent coeliac disease. CIA pattern, however, may be found in a minority of patients with other gastrointestinal disorders. A raised lactulose:mannitol ratio is also a non-specific marker of small intestinal dysfunction, and small bowel Crohn's disease and NSAID ingestion are common causes of abnormal small bowel permeability. Patients in this study had a normal small bowel meal and were not taking NSAIDs so this is unlikely to explain the findings.

What is the significance of a CIA pattern and abnormal intestinal permeability in these patients? Arranz and Ferguson ${ }^{6}$ reported on a group of 16 patients (with a variety of clinical presentations) with normal villous architecture and a positive CIA pattern; several (but not all) of these patients had high IEL counts or abnormal intestinal permeability. Nine of these patients were treated with a gluten free diet and seven had a complete or partial response. One of these seven patients had lymphocytic colitis, and had previously failed to respond to sulphasalazine and steroids. There is therefore some evidence that patients with microscopic colitis and a positive CIA pattern may respond to treatment with a gluten free diet. In the two patients in our series with a positive CIA pattern, the symptoms of diarrhoea were in remission at the time of the study, so the effects of a gluten free diet could not be evaluated. Patients with a CIA pattern may develop villous atrophy if given additional dietary gluten $^{6}$; one of our two patients with a positive
CIA pattern underwent gluten challenge but did not develop symptoms or villous atrophy.

Unfortunately, we did not obtain small intestinal aspirate in four of the nine patients, including one patient with abnormal intestinal permeability. One patient with collagenous colitis had abnormal intestinal permeability but a negative CIA pattern; the significance of this is not clear.

Serum antigliadin and anti-endomysial antibody levels were negative. This is not surprising, as positive serum antigliadin antibodies reflect the degree of villous atrophy, rather than gluten sensitivity per se. ${ }^{8}$ Anti-endomysial antibodies may be elevated in "latent" coeliac disease, but this is not a universal finding as there is a considerable dissociation between systemic and mucosal immune responses.

Coeliac disease is classically associated with the HLA types B8 and DQw2, but lymphocytic colitis is associated with the markers HLA A1 and Drw 53 while there is not a recognised HLA association with collagenous colitis. Furthermore, there is a striking female preponderance in collagenous colitis, which is not seen in coeliac disease or lymphocytic colitis. ${ }^{10}$ It is likely, therefore, that collagenous colitis and lymphocytic colitis are related but separate syndromes, and that factors other than gluten sensitivity are involved. Nevertheless, our data suggest that subtle small intestinal abnormalities occur frequently in both conditions, and merit further study.

We are indebted to Professor Anne Ferguson for analysing mucosal antigliadin antibodies. We thank Miss Julie Mackintosh for her help in typing the manuscript.

1 Read NW, Krejs GJ, Read MG, Santa Ana CA, Morawski SG, Fordtran JS. Chronic diarrhoea of unknown origin. Gastroenterology 1980;78:264-71.

2 Lazenby AJ, Yardley JH, Giardiello FM, Jessurun J, Bayless TM. Lymphocytic ("microscopic") colitis: a comparative histopathologic study with particular reference to collagenous colitis. Hum Pathol 1989;20:18-28.

3 Armes J, Gee DC, Macrae FA, Schroeder W, Bhathal PS. Collagenous colitis: jejunal and colorectal pathology. $\mathcal{F}$ Clin Pathol 1992;45:784-7.

4 Ferguson A, Arranz E, O'Mahony S. Clinical and pathological spectrum of coeliac disease-active, silent latent, potential. Gut 1993;34:150-1

5 O'Mahony S, Vestey JP, Ferguson A. Similarities in intestinal humoral immunity in dermatitis herpetiformis without enteropathy and in coeliac disease. Lancet 1990 335: $1487-90$.

6 Arranz E, Ferguson A. Intestinal antibody pattern in celiac disease: occurrence in patients with normal jejunal biopsy histology. Gastroenterology 1993;104:1263-72.

7 Cobden I, Dickinson RJ, Rothwell J, Axon ATR. Intestinal permeability assessed by excretion ratio of two molecules: permeability assessed by excretion ratio of two
results in coeliac disease. $B M \mathcal{F} 1978 ;$ ii: $1060-2$.

8 O'Mahony S, Arranz E, Barton JR, Ferguson A. Dissociation between systemic and mucosal humoral immune responses in coeliac disease. Gut 1991;32:29-35.

9 Giardiello FM, Lazenby AJ, Yardley JH, Bias WB, Johnson J, Alianiello RG, et al. Increased HLA A1 and diminished HLA A3 in lymphocytic colitis compared to controls and patients with collagenous colitis. Dig Dis Sci 1992;37:496-

10 Giardiello FM, Lazenby AJ, Bayless TM, Levine EJ, Bias WB, Ladenson PW, et al. Lymphocytic (microscopic) colitis: a clinicopathological study of 18 patients with comparisons to collagenous colitis. Dig Dis Sci 1989;34:1730-8. 